\title{
Teaching language components to deaf/hard-of-hearing and cochlear implant users: a literature review
}

Fernando Del Mando Lucchesi ${ }^{(1)}$ Ana Claudia Moreira Almeida-Verdu(2)

1) Universidade Federal de São Carlos, UFSCar, São Carlos, SP, Brazil.

(2) Universidade Estadual Paulista Júlio de Mesquita Filho, Campus Bauru, Bauru, SP, Brazil.

Research support source: Fundação de Amparo à Pesquisa do Estado de São Paulo and CNPq.

Conflict of interest: Nonexistent

Received on: April 19, 2017

Accepted on: October 02, 2017

\section{Mailing address:}

Fernando Del Mando Lucchesi

Faculdade de Ciências, UNESP Departamento de Psicologia

Av. Eng ${ }^{\circ}$ Edmundo Carrijo Coube s $/ n^{0}$ CEP: $17033-360$ - Bauru, São Paulo, Brasil

E-mail: fdmlucchesi@gmail.com

\section{ABSTRACT}

Cochlear implants are one of the possible ways for Deaf or Hard-of-Hearing (DHH) individuals to detect sounds and as a mean of insertion in the social, academic and work environments. Nevertheless, in many cases, the cochlear implant alone is not sufficient, demanding hearing and expressive language skills rehabilitation to optimize the device used. This study aimed at reviewing scientific articles that described empirical research with interventions and/or teaching methods of various language repertoires to deaf and hard-of-hearing cochlear implant users. The review was carried out in five scientific databases considering all periods. On the first phase, 156 articles were identified and from these, 24 publications were selected. After being read, these articles were categorized and analyzed as to the participants, teaching targets and procedures adopted. On the last stage of the research, 10 experimental studies were selected and analyzed regarding procedures and results, indicating important factors in teaching this population. The results point to the necessity of an increase of scientific production in the construction and evaluation of effective verbal repertoires teaching programs for cochlear implant users.

Keywords: Cochlear Implants; Teaching; Language Development; Review Literature as Topic 


\section{INTRODUCTION}

The population with severe hearing loss that does not benefit from common sound amplification devices may find in the cochlear implant $(\mathrm{Cl})$ an alternative way to detect sounds, sometimes for the first time. That is usually the case of pre-lingual (when hearing loss occurs before the establishment of oral language) deaf children. Nonetheless, even with the $\mathrm{Cl}$, educational interventions and a rehabilitation process is necessary in order to both auditory and oral production skills be developed by $\mathrm{Cl}$ users'.

The cochlear implant enables its user to detect sounds when present, but it is the auditory rehabilitation that aims to teach more complex repertoires: on one hand, discrimination between identical and different sounds, sound stimuli recognition, location of the sound source, auditory comprehension and memory'; and, on the other hand, oral production.

The process of learning auditory skills is important so those individuals can learn how to handle auditory stimuli as well as being able to express themselves through oral communication and interact with others around them. Pre-lingual deaf children show significant progress regarding auditory repertoires after one year experiencing cochlear implants, even though speaking skills does not follow the same improvement levels ${ }^{2}$. In longitudinal studies, which followed $\mathrm{Cl}$ users for 10 years, less than half $(40 \%)$ of Uziel et al. ${ }^{3}$ study population and $33 \%$ of the children assessed by Beadle et al. ${ }^{4}$ had intelligible speech for a regular listener (i.e., a listener without previous experience with $\mathrm{Cl}$ users on their daily basis).

In this regard, specialized literature point to difficulties for deaf and hard-of-hearing (DHH) population during literacy, with $\mathrm{Cl}$ users presenting educational achievement levels lower than their hearing peers. As a result, from those initial difficulties, the difference between deaf students and hearing students in reading and writing repertoires persists even after many years of $\mathrm{Cl}$ experience ${ }^{5}$.

Based on the level of expected achievements, it may be considered that this population would benefit from the teaching of auditory stimuli recognition and discrimination, especially those related to oral sounds and its extensions to oral production, focusing on more complexes repertoires like reading and writing. Therefore, on the account of auditory deprivation and other variables that can influence the learning process ${ }^{6}$, many $\mathrm{Cl}$ users present difficulties regarding the learning of those verbal repertoires (i.e., receptive and expressive repertoires). Considering this variables and needs, it is necessary to adopt teaching and intervention programs previously tested and structured based on empirical evidence of its effects. Therefore, the term "teaching" is understood here as any manipulation and/or arrangement of environment, materials and/or instructional elements aiming to change a behavior or response patterns with explicit criteria related to the intervention goal ${ }^{7}$. This process may be presented in different formats (incidental or direct/systematic), in different environments (e.g., school, clinic) and performed by different agents (e.g., teachers, caretakers, specialists).

Despite this necessity, literature reviews about $\mathrm{Cl}$ users point to a great number of skills assessment studies and few reporting teaching procedures. One of these literature review studies was conducted by Almeida-Verdu, da Silva e Golfeto ${ }^{8}$ in the Web of Science database with the terms: cochlear implant, speech, perception, recognition and language. This study found 86 articles published between 1998 and 2008. As a result from the analysis, they concluded that in that past decade the main target of the studies was to assess the effects of the implant on the users' receptive and expressive skills (42\% of the studies); however, little was found about the effects of particular instructional interventions on these skills. As stated by the authors, literature confirms the positive effects of the technology for deaf individuals; however, the lack of articles describing systematic instructional procedures teaching auditory and expressive skills with this population justify the interest in the subject.

Another literature review was published by $\mathrm{Neves}^{9}$ in 2015. The author aimed to survey and analyze publications about cochlear implant recipients using terms specifically related to expressive and receptive verbal repertoires. The review selected studies from 2003 to 2013 in Brazilian and international databases adopting the terms cochlear implants, auditory recognition, recognition, speech, speech production and language. As a result, the author also found 86 articles, in which $29 \%$ was about receptive and expressive skills assessment ad 34\% were theoretical studies, reviews about this population or longitudinal studies. The remaining studies aimed to characterize different groups among $\mathrm{Cl}$ users (e.g., comparing pre-lingual and postlingual groups). Among the studies selected by the author, none of them brought reports on verbal skills teaching procedures for users of cochlear implant. 
Given the fact that there are few studies describing the construction of educational programs (as much as curriculums and methods) $)^{8,9}$, the present study aimed to review the scientific literature regarding programs and/or methods of teaching receptive and expressive skills related to oral language and writing and reading to the deaf and cochlear implant users population. After the initial search, mentioned above, the objectives were to verify their incidence per year, participant's characteristics, target behaviors, adopted teaching procedures and main results achieved.

\section{METHODS}

The literature review was conducted in four phases divided as: search, selection, literature description and results analysis, described hereafter and illustrated in Figure 1:

$1^{\text {st }}$ Phase: Search for studies in Brazilian and international databases using keywords selected through DECS (Descritores em Ciências da Saúde - BIREME; Terms in Health Sciences) in both Portuguese and English. In PubMed, Web of Science and IBECs databases, the following keywords and Boolean operators were adopted: [cochlear implants] and [teaching] or [remedial teaching] or [curriculum] or [education of hearing disabled]. And in SciELO, LILACS and IBECs databases: [implante coclear] and [ensino] or [ensino de recuperação] or [currículo] or [educação de pessoas com deficiência auditiva].

In a first search, both terms described above and more specific terms related to this study targeted behaviors (i.e., "reading", "writing", "listening", "speech", "speech production", "speech recognition" and "speech intelligibility"). In that search, however, few publications were found. For this reason, a wider search was adopted during the first phase and a more laborious analysis was conducted during the subsequent phase.

$2^{\text {nd }}$ Phase: Selection of studies reporting procedures, curriculums and interventions to teach repertoires related to listening, speaking, reading and/or writing skills.

Through the abstract reading from the articles found during the first phase, the ones that described researches about teaching verbal repertoires directly or indirectly related to listening, speaking, reading and/or writing skills were selected. Publications that reported direct effects of well-known educational approaches to compare methods (e.g., auditory-oral, total communication, bilingual) were also selected in this phase.

In this phase, any publication that did not fulfill the inclusion criteria was excluded. Editorials, theoretical reviews, letters to editors and reports on skills assessment that were not contingent to the explicitly described teaching methods (that is, studies that only evaluated the $\mathrm{Cl}$ user independently of any teaching program) were also excluded. This last kind of report usually aims to identify the general status of the population in a wide environment; however, without specifying interventions that could explain these performances.

From the pool of articles selected during the first phase, $30 \%$ were chosen randomly to be analyzed by a second judge, in order to obtain the concordance index between observers. The index was characterized by the formula: number of concordances / number of concordances + number of disagreements $\times 100^{10}$. The result obtained was $94 \%$.

$3^{\text {rd }}$ Phase: Reading and analyzing full articles. In this phase, the selected publications were read and analyzed aiming to describe the following topics: a) Year of publication; b) Participants - diagnostics, hearing loss type and age; c) Goal - what specifically repertoires (dependent variables) were subjected to teaching procedures (independent variables); d) Design - if experimental (between groups or single subject) or if it was a case study; e) Method - About teaching procedures and stimuli adopted.

$4^{\text {th }}$ Phase: In this review's last phase, studies that presented detailed reports of experimental research's procedures and results were selected. These studies enabled a better analysis of dependent and independent variables with $\mathrm{Cl}$ users as target of direct teaching procedures. Therefore, studies with I) hearing participants, II) studies that reported retroactively data gathering from wider educational approaches and not specific interventions, III) and case studies with little or no experimental control were excluded. After this final selection, a classification and description of the adopted procedures and results were conducted. 


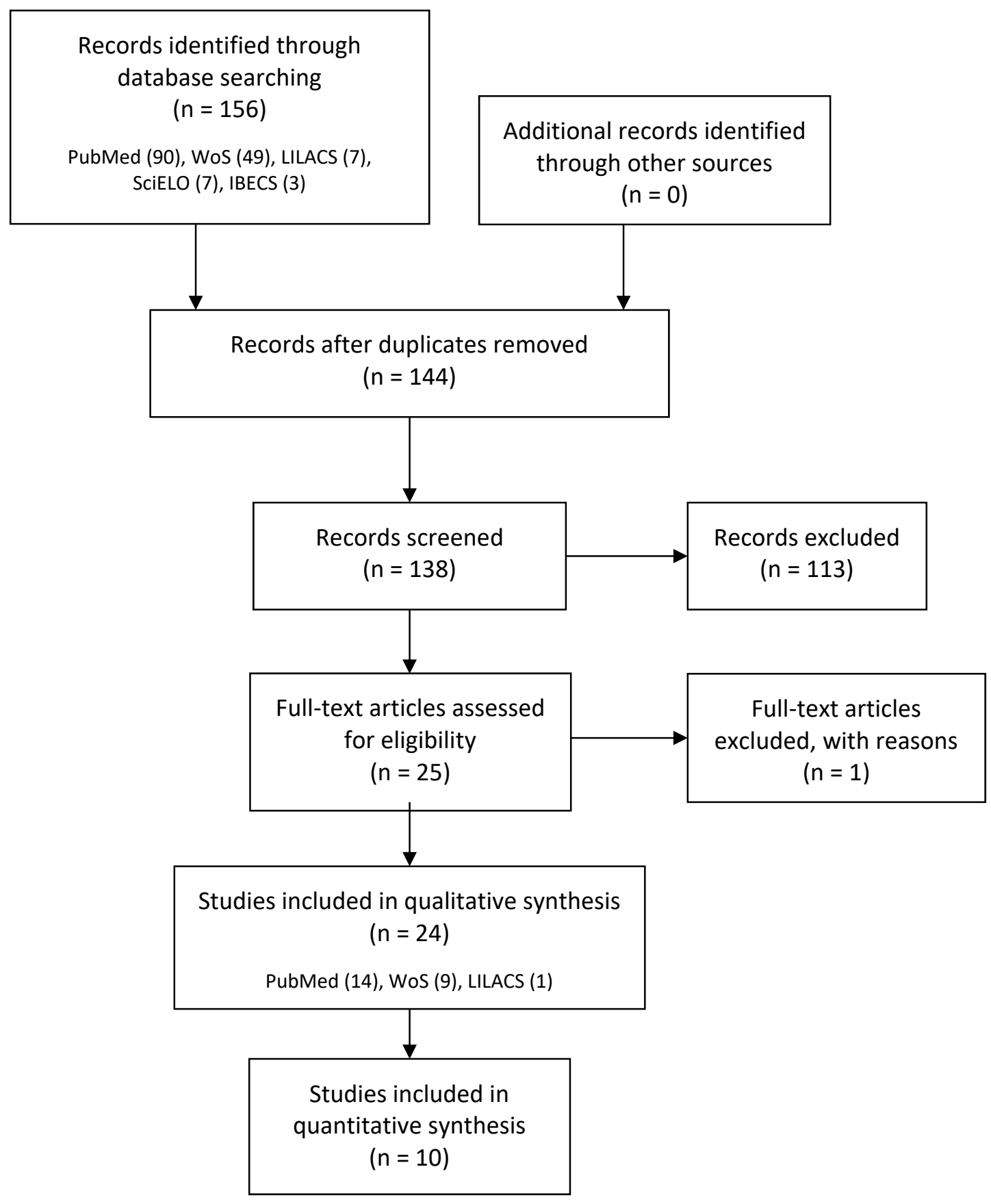

Source: Moher D, Liberati A, Tetzlaff J, Altman DG, The PRISMA Group. Preferred Reporting Items for Systematic Reviews and Meta-Analyses: The PRISMA Statement. PLOS Med. 2009;6(7):e1000097. Available at: doi:10.1371/journal.pmed1000097

Figure 1. Diagram: Study phases and number of publications found or selected by phase

\section{LITERATURE REVIEW}

Phase 1 - During this initial phase 156 articles were found. Most of them were found in the PubMed database: 90 publications. In the database Web of Science, 49 publications were selected. Thus, only 7, 7 and 3 articles were selected from the databases, respectively, LILACS, SciELO and IBECS. During this phase, 12 studies found in more than one database (already selected in other databases) were excluded, being this the only exclusion condition.

Data from the first phase is presented in Figure 1.

Phase 2 - In the second phase, articles that reported teaching or teaching methods of the targeted verbal repertoires were selected. These studies could have had different target behaviors, as reading, writing, speaking, listening, as well as other related behaviors 
(e.g., auditory recognition of melodies, vocalization of phonemes, reading of stories) and also conducted directly or indirectly with $\mathrm{Cl}$ users (e.g., intervention with peers and assessment of $\mathrm{Cl}$ users). From the 156 articles found during the first phase, 24 studies were selected. One of the publications previously selected was excluded after further analysis since cochlear implant users was not direct or indirect targets of the teaching intervention.

From the number of articles that were not selected, there were 59 evaluation studies, aiming as much as specific behaviors (e.g., auditory discrimination, speech production) as other repertories (e.g., social skills, influence of parental skills in the $\mathrm{Cl}$ user rehabilitation). Another 29 publications were theoretical studies. Among these publications, there were articles describing the work of care services to the population, theoretical studies on the evolution of the device itself and rehabilitation services, publications dealing with the education of deaf and hard-of-hearing children and others.

Still on the publications that were not selected, 10 studies were literature reviews on different related subjects. For example, the study conducted by Tucci, Trussell and Easterbrooks ${ }^{11}$ aimed to investigate strategies to teach phoneme-grapheme correspondence to children who are deaf and hard-of-hearing. Although the authors report teaching methods, the article was excluded because it is a literature review. Another 21 publications were excluded because they were: I) written in other languages (i.e., three studies in German, two in Russian, one in Polish and one in French); II) were editorials, letters to editors, or even experimental studies on different subjects (e.g., surgical procedures, $\mathrm{Cl}$ device technological improvements).

In general, it can be stated that most of publications $(41 \%)$ aimed to evaluate the population repertoires, despite $17 \%$ of studies aiming to empirically test teaching procedures of this repertoires. These results replicate data found by the literature reviews conducted by Almeida-Verdu, da Silva and Golfeto ${ }^{8}$ and Neves ${ }^{9}$, having a majority of evaluation studies. Although, in this review, a higher number of studies reporting teaching interventions were found. This difference may be explained by the adopted terms and more important, the time limit in both previous studies (2008 and 2014, respectively). As reported below, the number of such publications during the years 2014, 2015 and 2016 (13 publications) is greater than the number of studies published in all previous years (from 2000 to 2013, with 11 published articles) (Figure 2).

Phase 3 - The 24 articles selected during the previous phase were analyzed regarding the following topics: Publication year, Participants, Goal, Design and Method.

Regarding the publication year, the studies began to appear in the year 2000 with three publications ${ }^{12-14}$. Between 2002 and 2005 no publication of this kind was found. After this period, an increase in the number of published articles until the end of 2016 (search limit) can be seen. Figure 2 presents the simple (bars) and cumulative (line) frequency of the number of studies found per year.

Figure 2 shows the increase rate of publications aiming to evaluate teaching programs for the cochlear implanted population in the early 2000 's, especially in 2004. This increase may be explained by the implementation of public policies aiming to adopt cochlear implants as the main rehabilitation approach to deaf children, thus the therapeutic approach that prioritizes spoken language and inclusion of these children with the hearing population, was also adopted ${ }^{15}$. As an example of influent policies, laws created in the United States during the 2000's that aimed to prioritize evidence-based educational practices to teach reading in public schools. Such policies have made studies validating such practices indispensable. As stated by Tucci et al. ${ }^{11}$, as a product of these laws the need for evidence-based practices in reading teaching has also been extended to special education, which includes the deaf children population and $\mathrm{Cl}$ recipients.

Regarding the participants of these studies (Table 1), between 2 and 10 individuals participated in eight studies $^{16-23} ; 11$ to 20 individuals participated in seven studies $^{12,14,24-28}$. Seven studies had more than 21 participants ${ }^{13,29-34}$, in which three publications $\mathrm{s}^{29,31,33}$ had hearing participants as direct target of the interventions (e.g., parents, teachers and $\mathrm{Cl}$ users caretakers) aiming to evaluate its indirect effects on deaf children and $\mathrm{Cl}$ users' rehabilitation. Two studies were characterized as case studies and only one individual participated of each ${ }^{35,36}$ 


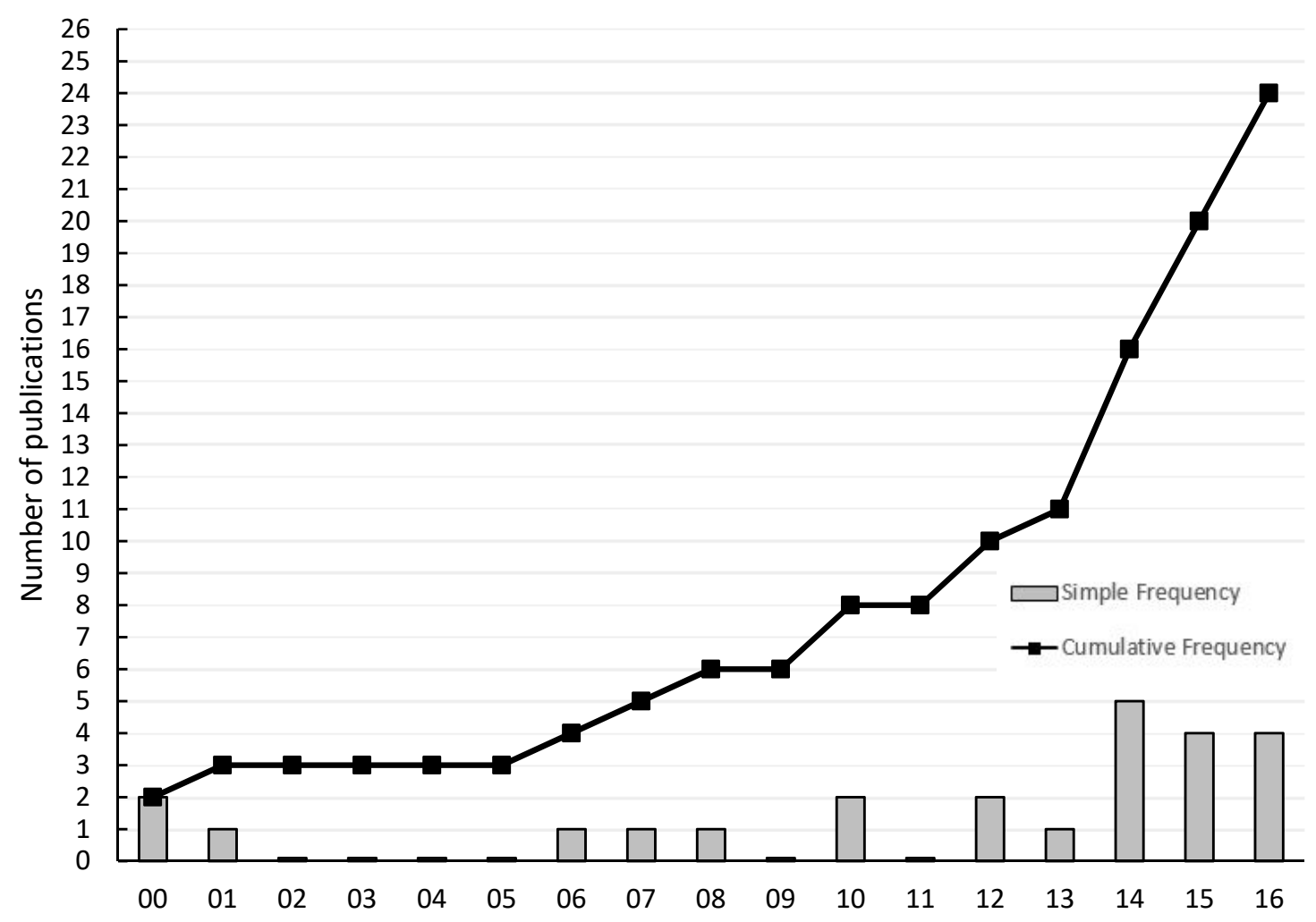

Figure 2. Simple (bars) and cumulative (line) frequency of selected publications on verbal repertoires teaching per year

Regarding the participants characterization, 19 studies were conducted with children under 11 years and only in three studies participated adolescents between 12 and 18 years. In six publications, the target population was adults (over 19 years of age), and among these, only one ${ }^{26}$ were deaf or hard-of-hearing.

Table 1 shows the description of the participants, as well as the difficulties to identify the participant's diagnostics. Most of the studies (13 publications) among those that provided directly or indirectly information about when the hearing loss occurred (some studies provide only the child's age at the time of diagnosis or at the time of implantation) - if pre-lingual or post-lingual - had pre-lingual deaf children as participants ${ }^{13,14,16-21,24,26,30,35,36}$. Only one study explicitly reported the participation of post-lingual deaf individuals ${ }^{26}$. Hearing individuals participated in interventions reported by seven studies $27-29,31-33,36$. Some of these studies, such as the publications from Suskind et al. ${ }^{33}$ and Clare Allen et al. ${ }^{31}$ aimed to establish teaching repertoires or increase the number of words and the quality of statements emitted in the context of the deaf and $\mathrm{Cl}$ user child - thus, creating conditions for the occurrence of incidental learning of these repertoires. Despite the importance of parents and teachers skills training and the enrichment of environments in which the child can present a high number of responses, enabling procedures of modeling and shaping, many studies in point to the need for direct, individual and programmed interventions in order to teach verbal repertoires to the population ${ }^{23}$. Thus, incidental exposure is necessary, but not sufficient. Regarding these possible procedures, while modeling is characterized by presenting the response and asking the child to imitate, shaping is the procedure of reinforcing each response until the child emits the desired final response $^{37}$.

Regarding the research designs used in the selected studies, most of them adopted experimental designs with between groups measures in 10 studies ${ }^{13,24,27-34}$ and single subject in 11 publications ${ }^{12,16,17,20-23,25,26}$. Three studies reported case studies or case series ${ }^{14,35,36}$.

Despite the importance of designs that enable a higher generalization and statistical analysis, case studies and single subject designs - usually with a low number of participants - also have an important role identifying and describing individual processes and potentially relevant variables. Single subject experimental designs are extremely versatile regarding evidences in research developed in educational 
Table 1. Distribution of participants by study and their characterization regarding age, diagnosis and rehabilitation device

\begin{tabular}{|c|c|c|c|c|c|c|c|c|c|c|}
\hline \multirow{2}{*}{ Publications } & \multirow{2}{*}{$\begin{array}{l}\text { Participants } \\
\text { Number }\end{array}$} & \multicolumn{3}{|c|}{ Diagnosis } & \multicolumn{2}{|c|}{ Device } & \multicolumn{4}{|c|}{ Participants by age } \\
\hline & & pre & post & hear & $\mathrm{Cl}$ & HA & $0-5$ & $6-11$ & $12-18$ & $19-59$ \\
\hline Lund and Douglas ${ }^{(23)}$ & 9 & \multicolumn{2}{|c|}{9} & 0 & 6 & 3 & 9 & 0 & 0 & 0 \\
\hline Douglas ${ }^{(34)}$ & 22 & \multicolumn{2}{|c|}{22} & 0 & 15 & 7 & 16 & 6 & 0 & 0 \\
\hline Suskind et al. ${ }^{(33)}$ & 44 & \multicolumn{2}{|c|}{11} & 22 & 11 & 11 & 22 & 0 & 0 & 22 \\
\hline Richels et al. ${ }^{(18)}$ & 3 & 3 & 0 & 0 & 1 & 2 & 3 & 0 & 0 & 0 \\
\hline Messier and Wood ${ }^{(25)}$ & 18 & \multicolumn{2}{|c|}{18} & 0 & 18 & 0 & \multicolumn{2}{|c|}{18} & 0 & 0 \\
\hline Bobzien et al. (19) & 4 & 4 & 0 & 0 & 1 & 3 & 4 & 0 & 0 & 0 \\
\hline Anastacio-Pessan et al. (20) & 6 & 4 & 2 & 0 & 6 & 0 & 0 & 3 & 3 & 0 \\
\hline Lucchesi et al. (21) & 2 & 2 & 0 & 0 & 2 & 0 & 0 & 2 & 0 & 0 \\
\hline Clare Allen et al. ${ }^{(31)}$ & 51 & 0 & 0 & 51 & 0 & 0 & 0 & 0 & 0 & 51 \\
\hline Nakeva von Mentzer et al. (32) & 48 & \multicolumn{2}{|c|}{32} & 16 & 17 & 15 & \multicolumn{2}{|c|}{48} & 0 & 0 \\
\hline Lew et al. (22) & 3 & \multicolumn{2}{|c|}{3} & 0 & 1 & 2 & 3 & 0 & 0 & 0 \\
\hline Lund and Schuele ${ }^{(17)}$ & 5 & 5 & 0 & 0 & 5 & 0 & 5 & 0 & 0 & 0 \\
\hline Raver et al. ${ }^{(16)}$ & 4 & 4 & 0 & 0 & 2 & 2 & 4 & 0 & 0 & 0 \\
\hline Innes-Brown et al. (24) & 20 & \multicolumn{2}{|c|}{11} & 9 & 6 & 5 & 0 & 12 & 6 & 0 \\
\hline Faulkner et al. ${ }^{(29)}$ & 48 & 0 & 0 & 48 & 0 & 0 & 0 & 0 & 0 & 48 \\
\hline Kosaner et al. ${ }^{(30)}$ & 25 & \multicolumn{2}{|c|}{25} & 0 & 25 & 0 & \multicolumn{2}{|c|}{25} & 0 & 0 \\
\hline Smith and Wang ${ }^{(35)}$ & 1 & 1 & 0 & 0 & 1 & 0 & 1 & 0 & 0 & 0 \\
\hline Stacey et al. (26) & 11 & 5 & 6 & 0 & 11 & 0 & 0 & 0 & 0 & 11 \\
\hline Stacey and Summerfield (27) & 18 & 0 & 0 & 18 & 0 & 0 & 0 & 0 & 0 & 18 \\
\hline Nogaki et al. ${ }^{(28)}$ & 18 & 0 & 0 & 18 & 0 & 0 & 0 & 0 & 0 & 18 \\
\hline Torres et al. ${ }^{(36)}$ & 1 & 1 & 0 & 0 & 1 & 0 & 1 & 0 & 0 & 0 \\
\hline Abdi et al. ${ }^{(14)}$ & 14 & 14 & 0 & 0 & 14 & 0 & 7 & 6 & 1 & 0 \\
\hline Connor et al. ${ }^{(13)}$ & 147 & 147 & 0 & 0 & 147 & 0 & 0 & 147 & 0 & 0 \\
\hline \multirow[t]{2}{*}{ Schopmeyer et al. (12) } & 11 & \multicolumn{2}{|c|}{11} & 0 & 11 & 0 & \multicolumn{2}{|c|}{11} & 0 & 0 \\
\hline & 533 & 332 & 150 & 182 & 301 & 50 & 177 & 278 & 10 & 168 \\
\hline
\end{tabular}

Note: The shaded numbers identify values for mean age (e.g., Connor et al. ${ }^{(13)}$ ) or undeclared data for the period in which hearing loss occurred (diagnosis, whether pre or post-lingual) in 9 studies.

contexts (especially on teaching new skills). This type of research is characterized by an experimental design, more than only correlational or descriptive, about the relation between dependent and independent variables. Thus, making it easier to manipulate variables actively and appropriately to investigate the effects of teaching interventions. Byiers, Reichle and Symons ${ }^{38}$ propose that the single subject design represents an important tool in the development and implementation of evidence-based practice in communication disorders and sciences. However, an intrinsic need of this design is the systematic replication of studies, which would guarantee both the internal and external validity of the procedure ${ }^{38}$. An evidence found here and pointed out by other reviews ${ }^{11}$ is that such replications are often not developed and, at most, follow-up studies may be found (that is, replications with modifications, either in the method or in the population), thus, not enabling replication of results in a systematic way.

Regarding the type of intervention, nine studies reported teaching procedures in groups and 18 (the majority) reported individual procedures; it is important to point that some studies make use of both types of procedures. Many of the selected publications did not report the duration and number of sessions of the described interventions with high variability between studies and participants in the same study. Nevertheless, three interventions lasted for less than three weeks; eight studies lasted for six to 11 weeks; and five studies lasted for 11 to 15 weeks. Among the remaining publications, four reported interventions that took about six months and only two studies had 
a duration of one year. Two studies were conducted retrospectively, using data from participants exposed to interventions for more than two years ${ }^{13,34}$.

The analysis and categorization of the objectives is important in order to describe the dependent variables of the selected studies and possible effects when they are under the influence of independent variables. In the context of this type of studies these variables are the target behaviors and teaching procedures. The objectives of each study were quite varied within the range of receptive and expressive language skills. As an auditory skill target behavior, studies that aimed to teach sound discrimination under different stimulatory conditions (such as letters, words and/or sentences sounds) were selected, even when there were secondary learning of other skills (e.g., strengthening of reading repertoires during tasks of word discrimination after listening to the word sound). Likewise, studies that aimed to teach speech production were those in which teaching procedures focused primarily on oral language, as well as a type of response (under different stimulatory conditions, such as pictures to name, words to repeat or speech of another person to interact) and in the frequency of emitted responses. As reading and writing teaching studies were classified publications in which the focus was on the population literacy, regardless of secondary gains.

Most of the articles (15) reported goals related to speech production (oral expressive). Another 13 studies had as objective auditory discrimination skills (of dictated phonemes, syllables and receptive vocabulary) while only five articles reported reading skills teaching ${ }^{17,20,21,32,35}$.

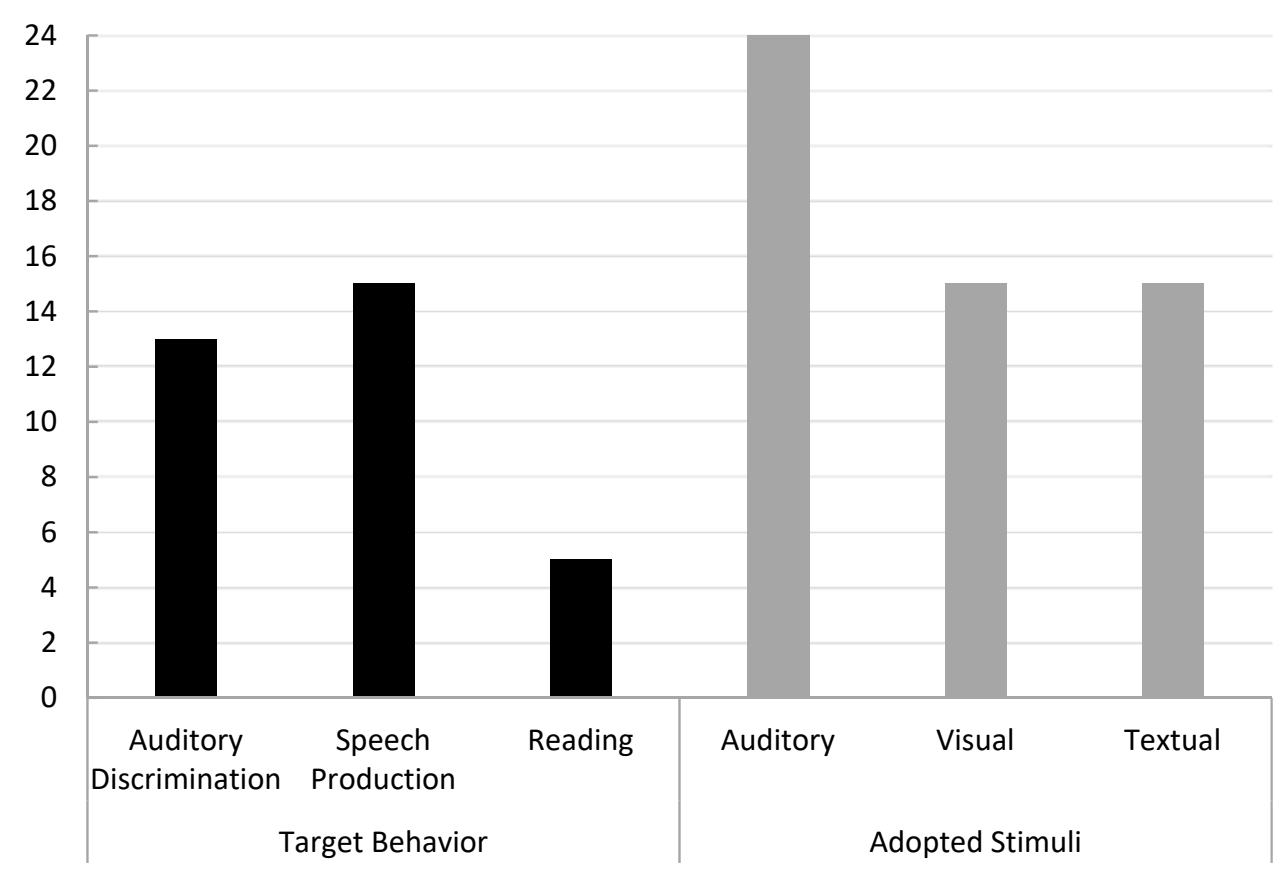

Figure 3. Target behaviors and adopted stimuli in the selected publications by number of articles

As shown in Figure 3, although few studies aimed reading skills teaching - that may be considered a type of speech production but differ by the nature of the stimulus presented - 15 interventions used textual stimuli as printed words, letters and syllables. All the selected studies utilized auditory stimuli (e.g., dictated words, music, story reading) during teaching and testing procedures and 15 publications reported the use of non-textual visual stimuli (i.e., pictures, drawings).
The training procedures on auditory skills of three studies were based on music teaching ${ }^{14,24,30}$. These studies adopted group interventions focusing on musical stimuli detection and discrimination. Besides, among other materials used there were book reading, described in three publications ${ }^{16,19,25}$, in which different repertoires were targeted. In these studies, the books had the function to contextualize the words dictated by the teacher/researcher, without a specific teaching purpose. 
Among the studies that reported expressive skills training, the one conducted by Smith and Wang ${ }^{35}$ focused on phonological awareness and reading through the Visual Phonics program and a phonological awareness curriculum using textual, auditory and visual stimuli. This and other studies ${ }^{20,21}$ discuss the relation between speech production and reading. Other publications aiming for speech production reported different approaches, such as the Cued Speech, adopted by Torres, Moreno-Torres e Santana ${ }^{36}$. Similar to the study conducted by Smith and Wang ${ }^{35}$, this publication is also a case study in which prompts were used during training (prompts usually are described as instructions or clues before the participant's response, such as gestural clues during recognition and discrimination of auditory stimuli and textual in speech production training).

In total, nine studies adopted receptive and expressive teaching procedures through computerized programs. Among these publications, six ${ }^{20,21,25,27-29,32}$ presented tasks known as Matching to Sample (MTS) for hearing participants, however, emulating the sound stimuli produced by the cochlear implant to deaf individuals. Therefore, these studies aimed to improve teaching methods to the population of $\mathrm{Cl}$ users through conditional relations training between dictated words, sentences and phonemes and their respective textual stimuli.

In the Matching to Sample procedure, one stimulus is presented as sample and the task is to select the right comparison stimulus presented simultaneously among others. This procedure is very flexible and enables training of stimuli relations of different natures. An example of a MTS task is a training of auditoryvisual discrimination in which the auditory stimulus is dictated to the participant and the comparison stimuli are pictures, objects or printed textual stimuli.

Although the literature highlights the difficulties of the population during literacy and regarding the aforementioned studies that use these repertoires during auditory trainings, few articles among the selected ones aimed to teach reading repertoires. According to the study conducted by Tucci et al. ${ }^{11}$ on teaching methods of reading repertoires to $\mathrm{DHH}$ individuals, the research field is still scarce, with few studies and fewer replications. The authors describes the following methods as the most prominent: I) Cued Speech In which the relationship between graphemes and phonemes is taught through speech with specific gestural cues; II) Visual Phonics - a sign language, but different from ASL (North American Sign Language); III) Speechreading - A combination of visual cues through lip reading; IV) Fingerspelling - Teaching of graphemephoneme relations through a digital alphabet, varying between digital alphabet and more complex signs; V) Iconic / Semantic Representation - Teaching through relationships between figures, letters and words; and 6) Morpheme - Teaching word formation and its effects on reading and its generalization.

From the selected publications, four reported interventions to teach reading ${ }^{17,20,21,35}$. Smith e Wang ${ }^{35}$ adopted the Visual Phonics and a phonological awareness curriculum. In the study published by Lund e Schuele ${ }^{17}$, five preschoolers and $\mathrm{Cl}$ users participated in reading trainings aiming to develop vocabulary through relations between pictures and words. The only two studies conducted in Brazil ${ }^{20,21}$ focused on teaching or strengthening reading repertoires to increase levels of speech production with greater accuracy in other types of tasks using programmed and computerized teaching with implanted children. In these studies, considering that written word provides graphical clues for a more accurate speech production during reading tasks, a more precise speech during picture naming tasks can be obtained after training or strengthening of reading repertoires (and the relations between dictated words, printed words and pictures) ${ }^{39}$. These data confirm and amplify Tucci et al. ${ }^{11}$ findings on the teaching of reading repertoires to the $\mathrm{DHH}$ population with a focus on the relationships between graphemes, phonemes and other types of visual cues (e.g., signs and figures).

$4^{\text {th }}$ Phase - In the last analysis phase of the review, 10 studies were selected from the 24 previously described. General data on procedures and results are described in Table 2. 
Table 2. Phase 4: Teaching targets, procedures and results

\begin{tabular}{|c|c|c|c|c|}
\hline Publication & Target & Procedures & Participants & Results \\
\hline Lund and Douglas ${ }^{(23)}$ & $\begin{array}{l}\text { Expressive } \\
\text { Vocabulary }\end{array}$ & $\begin{array}{l}\text { Word contextualizing (describing } \\
\text { things), imitation, auditory-visual } \\
\text { MTS, naming. }\end{array}$ & $\begin{array}{l}\text { Nine. Between } 4 \text { and } \\
5 \text { years old. Six using } \mathrm{Cl} \text {. }\end{array}$ & $\begin{array}{c}\text { Experimental group learned a mean of } 5 \text { words per } \\
\text { week. In contrast, } 0.5 \text { words were learned by incidental } \\
\text { teaching per week. }\end{array}$ \\
\hline Richels et al. ${ }^{(18)}$ & $\begin{array}{l}\text { Expressive } \\
\text { Vocabulary }\end{array}$ & $\begin{array}{l}\text { Response shaping and modeling } \\
\text { technics through hearing peers that } \\
\text { described actions. }\end{array}$ & $\begin{array}{l}\text { Three. Between } 3 \text { and } \\
4 \text { years old. One } \mathrm{Cl} \text { user. }\end{array}$ & $\begin{array}{c}\mathrm{P} 1 \text { and } \mathrm{P} 3 \text { achieved criteria after six sessions, while P2 } \\
\text { needed } 20 \text { sessions (and did not show maintenance of } \\
\text { performance after a few weeks) }\end{array}$ \\
\hline Messier and Wood (25) & $\begin{array}{l}\text { Expressive } \\
\text { Vocabulary }\end{array}$ & $\begin{array}{l}\text { Digital book reading with parents. } \\
\text { Programmed activities (context and } \\
\text { phonetic focused). Control: just } \\
\text { reading. }\end{array}$ & $\begin{array}{l}18 \text { children between } 4 \text { and } \\
9 \text { years old. All Cl users. }\end{array}$ & $\begin{array}{l}\text { Experimental group showed better word definition, } \\
\text { expressive and receptive vocabulary than control group. }\end{array}$ \\
\hline $\begin{array}{l}\text { Anastacio-Pessan } \\
\text { et al. }{ }^{(20)}\end{array}$ & $\begin{array}{l}\text { Expressive } \\
\text { Vocabulary }\end{array}$ & $\begin{array}{l}\text { Auditory-visual MTS programmed } \\
\text { trials using pictures, words and } \\
\text { syllables. }\end{array}$ & $\begin{array}{l}\text { Six. Between } 11 \text { and } \\
14 \text { years old. All Cl users. }\end{array}$ & $\begin{array}{l}\text { All children learned the taught relations. Four } \\
\text { participants showed improved naming performance. } \\
3 \text { presented generalization to new pictures. }\end{array}$ \\
\hline Lucchesi et al. (21) & $\begin{array}{l}\text { Expressive } \\
\text { Vocabulary }\end{array}$ & $\begin{array}{l}\text { Auditory-visual MTS programmed } \\
\text { trials using pictures, words and } \\
\text { syllables. }\end{array}$ & $\begin{array}{l}\text { Two. Between } 7 \text { and } \\
8 \text { years old. Both } \mathrm{Cl} \text { users. }\end{array}$ & $\begin{array}{l}\text { Both children presented improvements during picture } \\
\text { naming tasks. }\end{array}$ \\
\hline $\begin{array}{l}\text { Nakeva von Mentzer } \\
\text { et al. }{ }^{(32)}\end{array}$ & Reading & $\begin{array}{l}\text { Auditory-visual MTS programmed } \\
\text { trials with letters, syllables and } \\
\text { words. Difficulty progression. }\end{array}$ & $\begin{array}{l}\text { DHH group- } 32 \text { ( } 4 \text { to } 7 \\
\text { years, } 17 \mathrm{Cl}) . \text { Hearing } \\
\text { group- } 16 \text { ( } 5 \text { to } 8 \text { years). }\end{array}$ & $\begin{array}{l}\text { Both groups improved. DHH had lower baseline } \\
\text { performances. Hearing group was better at sentence } \\
\text { comprehension and word decoding. }\end{array}$ \\
\hline Lew et al. (22) & $\begin{array}{c}\text { Auditory } \\
\text { Discrimination }\end{array}$ & $\begin{array}{l}\text { Auditory-visual MTS trials. } \\
10 \text { difficulty levels of auditory } \\
\text { discrimination. }\end{array}$ & $\begin{array}{l}\text { Three. Between } 2 \text { and } \\
3 \text { years old. One } \mathrm{Cl} \text { user. }\end{array}$ & $\begin{array}{l}\text { All showed improvements at least in two points }(0-10) \\
\text { accordingly to their tests. Only one participant showed } \\
\text { improvement by standardized tests. }\end{array}$ \\
\hline Lund and Schuele ${ }^{(17)}$ & $\begin{array}{l}\text { Expressive } \\
\text { Vocabulary }\end{array}$ & $\begin{array}{l}\text { Vocal imitation and picture } \\
\text { contextualization tasks. }\end{array}$ & $\begin{array}{l}\text { Five. Between } 3 \text { and } \\
5 \text { years old. All Cl users. }\end{array}$ & $\begin{array}{c}\text { Regarding auditory discrimination, participants showed } \\
\text { improvements. However little improvement in expressive } \\
\text { vocabulary was observed. }\end{array}$ \\
\hline Stacey et al. (26) & $\begin{array}{c}\text { Auditory } \\
\text { Discrimination }\end{array}$ & $\begin{array}{l}\text { Discrimination tasks of isolated } \\
\text { words and words within } \\
\text { sentences (computerized and self- } \\
\text { administered) }\end{array}$ & $\begin{array}{l}\text { 11. Between } 23 \text { and } \\
71 \text { years old. Cl users. }\end{array}$ & $\begin{array}{l}8 \text { participants completed the entire program. } \\
\text { Improvements in consonants discrimination, but not } \\
\text { with vowels and sentences. }\end{array}$ \\
\hline Schopmeyer et al. (12) & $\begin{array}{l}\text { Auditory } \\
\text { Discrimination }\end{array}$ & $\begin{array}{l}\text { Fast ForWord program. Many } \\
\text { programmed tasks. In general, } \\
\text { auditory discrimination tasks with } \\
\text { difficulty progression. }\end{array}$ & $\begin{array}{l}\text { 11. Mean age of seven } \\
\text { years old. All Cl users. }\end{array}$ & $\begin{array}{l}\text { All children showed improvements on } 5 \text { standardized } \\
\text { tests of receptive and expressive language. }\end{array}$ \\
\hline
\end{tabular}

Among the 10 selected articles only two studies adopted group comparison designs, in contrast to eight studies that adopted single subject designs. Most of the publications reported interventions aiming to teach expressive vocabulary, in which the main dependent variable was oral responses while naming objects, pictures or answering questions of the researcher regarding these stimuli (e.g., to describe or define an object). In these studies, teaching procedures varied widely between tasks of vocal imitation ${ }^{17,18,23}$, receiving instruction on the definition of stimuli 17,23,25, attempts at auditory-visual MTS ${ }^{20,21}$. The results were mostly positive, but with great variability among participants when the research presented individual data.

Three studies used MTS tasks aiming to teach auditory discriminations between stimuli dictated by the researcher and pictures and printed letters, syllables and words as comparison stimuli. These types of intervention point to the importance of the adoption of discrete trials with carefully programmed tasks beginning with instruction (prompt), followed by the participant's response and feedback. The only study that did not report high performance results from the participants was conducted by Stacey et al..$^{26}$, in which the adopted teaching program was self-administered by adult $\mathrm{Cl}$ users (ages between 23 and 71 years old). Only eight out of 11 participants in this intervention complete the entire teaching program (15 hours) and out of this eight, only two reported a better auditory discrimination performance when completing a satisfaction questionnaire. There are many differences between this intervention and others described here. The differences found between this intervention and others are many. In addition to the adoption of a very heterogeneous group of adults, there is a lack of difficulty progression (starting with easier stimuli towards more difficult stimuli) and criteria of performance - to repeat training steps in the presence of wrong answers -, variables found in other studies of the same type.

Finally, the only study that had as main objective the teaching of reading repertoires was developed by Nakeva von Mentzer ${ }^{32}$, aiming to compare the learning 
processes of reading between a group of children with $\mathrm{Cl}$ and a control group of hearing children. This study also used computerized programmed teaching characterized by discrete trials of auditory-visual MTS. It is worth mentioning that the studies of Anastácio-Pessan et al. ${ }^{20}$ and Lucchesi et al. ${ }^{21}$, targeting oral production responses, also adopted reading training through computerized programs as a route for the development of accurate speech production (expressive vocabulary).

Some conclusions can be drawn in the analysis of the articles selected in the last phase of this review study, regarding the effectiveness of verbal repertoire teaching methods for the deaf population and users of $\mathrm{Cl}$ : I) The importance of individualized teaching (computerized or not), based on discrete trials, with explicit learning criteria and repeating/correction opportunities in case of wrong answers ${ }^{17,18,20-23,32}$; II) The importance of interventions centered on the participant's responses, in opposition to other teaching methods based on incidental learning ${ }^{23,25}$; and III) The possibility of learning repertoires not taught directly through careful teaching programming (such as training auditory discrimination of diverse stimuli and gains in speech production) ${ }^{20-22}$. This last point is controversial and needs further investigation, since the intervention adopted in the study of Lund and Schuele ${ }^{17}$ did not demonstrate this capacity of generalization by all participants; however, the number of opportunities for speech production responses during the training phases seems to be a distinction between these studies.

It is important to mention that some publications known beforehand by the authors were not selected by the method and terms adopted, even if they were aligned with the targeted literature (publications reporting teaching of verbal repertoires to the $\mathrm{Cl}$ recipients population). Although these studies were associated with the used databases, they did not use terms related to "teaching" or "cochlear implant", often adopting nonstandard keywords, which may better describe the study, however restricting their access in review studies. The choice of standardized terms in opposition to other keywords is important considering the large number of publications, in order to promote visibility between researchers and professionals ${ }^{40}$. This consideration does not eliminate possible limitations of this review study (that used a small number of terms in the initial survey and did not seek studies from other sources), therefore, it is necessary that future review studies take into account other terms and search methods and analysis of the publications in this field.

\section{CONCLUSION}

According to the results, although the number of studies that reported teaching interventions are small, a greater number of these publications were found in relation to previous studies 8,9 and increased in the last three years. However, the number of studies reporting interventions is still small compared to evaluation studies. The targeted population of teaching interventions are mostly children under 11 years old, with pre-lingual hearing loss and cochlear implanted. Regarding the targeted repertoires, training of auditory discrimination and expansion of oral vocabulary have been the main teaching objectives of these studies. Finally, regarding the results of these studies, there are evidences that point to the importance of individualized procedures and direct teaching, in opposition to group interventions through incidental learning. These data suggest, therefore, the increase in the investment in teaching programs of different verbal abilities, especially related to reading and writing. It also makes clear the importance of studies conducted with greater experimental control and, mainly, based on systematic replications to increase the generality of the obtained data.

\section{REFERENCES}

1. Bevilacqua MC, Formigoni GMP. Audiologia educacional: Uma opção terapêutica para a criança deficiente auditiva. Carapicuíba: Pró-Fono; 2000.

2. Ertmer DJ, Goffman L. Speech production accuracy and variability in young cochlear implant recipients: comparisons with typically developing age-peers. $J$ speech lang hear res. 2011;54(1):177-89.

3. Uziel AS, Sillon M, Vieu A, Artieres F, Piron JP, Daures JP et al. Ten-year follow-up of a consecutive series of children with multichannel cochlear implants. Otol Neurotol. 2007;28(5):615-28.

4. Beadle EAR, McKinley DJ, Nikolopoulos TP, Brough J, O'Donoghue GM, Archbold SM. Long-term functional outcomes and academicoccupational status in implanted children after 10 to 14 years of cochlear implant use. Otol Neurotol. 2005;26(6):1152-60.

5. Weisi F, Rezaei M, Rashedi V, Heidari A, Valadbeigi A, Ebrahimi-Pour M. Comparison of reading skills between children with cochlear implants and 
children with typical hearing in Iran. Int j pediatr otorhinolaryngol. 2013;77(8):1317-21.

6. Boons T, Brokx JPL, Shooge I, Frijins JHM, Peeraer $L$, Vermeulen A et al. Predictors of spoken language development following pediatric cochlear implantation. Ear Hear. 2012;33(5):627-39.

7. Kubo O, Botomé SP. Ensino-Aprendizagem: uma interação entre dois processos comportamentais. Interação. 2001;5(1):123-32.

8. Almeida-Verdu ACM, da Silva WR, Golfeto RM. Linguagem e comportamento verbal em surdos implantados: revisão da literatura e perspectivas de estudos. Anais do III Congresso Brasileiro de Educação Especial; 2-5 Dez 2008; São Carlos; 2008.

9. Neves AJ, Almeida-Verdu ACM, Moret ALM, Silva LTN. The implications of the cochlear implant for development of language skills: A literature review Rev. CEFAC. 2015;17(5):1643-56.

10. Kazdin AE. Single-case research designs: methods for clinical and applied settings. New York: Oxford University Press; 1982.

11. Tucci SL, Trussell JW, Easterbrooks SR. A review of the evidence on the strategies for teaching children who are $\mathrm{DHH}$ grapheme-phoneme correspondence. Commun Disord Q. 2014;35(4):191-203. Doi: $10.1177 / 1525740114523776$

12. Schopmeyer B, Mellon N, Dobaj H, Grant G, Niparko JK. Use of Fast ForWord to enhance language development in children with cochlear implants. Ann Otol Rhinol Laryngol. Suppl. 2000;185:95-8.

13. Connor CM, Hieber S, Arts HA, Zwolan TA. Speech, Vocabulary, and the education of children using cochlear implants: oral or total communication? J Speech Lang Hear Res. 2000;43(5):1185-204.

14. Abdi S, Khalessi MH, Khorsandi M, Gholami B. Introducing music as a means of habilitation for children with cochlear implants. Int $\mathrm{J}$ Pediatr Otorhinolaryngol. 2001;59(2):105-13.

15. Sarant J. cochlear implants in children: a review. In: Naz S. (ed.) Hearing Loss. Shanghai: InTech; 2012. p. 40-75.

16. Raver SA, Bobzien J, Richels C, Hester P, Anthony N. Using dyad-specific social stories to increase communicative and social skills of preschoolers with hearing loss in self-contained and inclusive settings. International Journal of Inclusive Education. 2014;18(1):18-35. Doi: 10.1080/13603116.2012.756543
17. Lund E, Schuele CM. Effects of a word-learning training on children with cochlear implants. J Deaf Stud Deaf Educ. 2014;19(1):68-84.

18. Richels CG, Schwartz KS, Bobzien JL, Raver SA. Structured instruction with modified storybooks to teach morphosyntax and vocabulary to preschoolers who are deaf/hard of hearing. J Deaf Stud Deaf Educ. 2016;21(4):352-61. Doi: 10.1093/ deafed/enw049.

19. Bobzien JL, Richels C, Schwartz K, Raver SA, Hester $\mathrm{P}$, Morin L. Using repeated reading and explicit instruction to teach vocabulary to preschoolers with hearing loss. Infants Young Child. 2015;28(3):262-80. Doi: 10.1097/ IYC.0000000000000039

20. Anastácio-Pessan FL, Almeida-Verdu ACM, Bevilacqua MC, de Souza DG. Usando o paradigma de equivalência para aumentar a correspondência na fala de crianças com implante coclear na nomeação de figuras e na leitura. Psicol Reflex Crít. 2015;28(2):365-77.

21. Lucchesi FD, Almeida-Verdu ACM, Buffa MJMB, Bevilacqua MC. Efeitos de um programa de ensino de leitura sobre a inteligibilidade da fala de crianças usuárias de implante coclear. Psicol Reflex Crít. 2015;28(3):500-10.

22. Lew J, Purcell AA, Doble M, Lim LH. Hear here: children with hearing loss learn words by listening. Int J Pediatr Otorhinolaryngol. 2014;78(10):1716-25.

23. Lund E, Douglas M. Teaching vocabulary to preschool children with hearing loss. Except child. 2016;83(1):26-41. Doi: 10.1177/0014402916651848

24. Innes-Brown H, Marozeau JP, Storey CM, Blamey PJ. Tone, rhythm, and timbre perception in school-age children using cochlear implants and hearing aids. J Am Acad Audiol. 2013;24(9):789-806.

25. Messier J, Wood C. Facilitating vocabulary acquisition of children with cochlear implants using electronic storybooks. J Deaf Stud Deaf Educ. 2015;20(4):356-73. Doi:10.1093/deafed/env031.

26. Stacey PC, Raine CH, O'Donoghue GM, Tapper L, Twomey T, Summerfield AQ. Effectiveness of computer-based auditory training for adult users of cochlear implants. Int J Audiol. 2010;49(5):347-56.

27. Stacey PC, Summerfield AQ. Comparison of word-, sentence-, and phoneme-based training strategies in improving the perception of spectrally distorted speech. J speech lang hear res. 2008;51(2):526-38. 
28. Nogaki G, Fu Q, Galvin III JJ. The effect of training rate on recognition of spectrally shifted speech. Ear Hear. 2007;28(2):132-40.

29. Faulkner A, Rosen S, Green T. Comparing live to recorded speech in training the perception of spectrally shifted noise-vocoded speech. J Acoust Soc Am. 2012;132(4):336-42.

30. Kosaner J, Kilinc A, Deniz M. Developing a music programme for preschool children with cochlear implants. Cochlear Implants Int. 2012;13(4):237-47.

31. Clare Allen M, Kendrick A, Archbold S, Harrigan S. LEAPing on with language: An on-line language programme to support classroom teachers and parents of primary school children (aged 5-11 years). Cochlear Implants Int. 2014;15(S1):36-8. Doi:10.1179/1467010014Z.000000000169

32. Nakeva von Mentzer C, Lyxell B, Sahlén B, Dahlström O, Lindgren M, Ors $\mathrm{M}$ et al. Computerassisted reading intervention with a phonics approach for children using cochlear implants or hearing aids. Scand J Psychol. 2014;55(5):448-55. Doi: 10.1111/sjop.12149.

33. Suskind DL, Graf E, Leffel KR, Hernandez MW, Suskind E, Webber $R$ et al. Project ASPIRE: Spoken language intervention curriculum for parents of low-socioeconomic status and their Deaf and Hard-of-Hearing Children. Otol Neurotol. 2016;37(2):110-17. Doi: 10.1097/ MAO.0000000000000931.

34. Douglas M. Improving spoken language outcomes for children with hearing loss: Data-driven Instruction. Otol Neurotol. 2016;37(2):13-9. Doi: 10.1097/MAO.0000000000000902.

35. Smith A, Wang Y. The impact of visual phonics on the phonological awareness and speech production of a student who is deaf: a case study. Am Ann Deaf. 2010;155(2):124-30.

36. Torres S, Moreno-Torres I, Santana R. Quantitative and qualitative evaluation of linguistic input support to a prelingually deaf child with cued speech: A case study. J Deaf Stud Deaf Educ. 2006;11(4):438-48.

37. Almeida-Verdu ACM, Golfeto R. Condições de ensino da linguagem: dicas para pais e profissionais. Bauru: Joarte Gráfica e Editora; 2012.

38. Byiers BJ, Reichle J, Symons FJ. Single-subject experimental design for evidence-based practice. Am J Speech Lang Pathol. 2012;21(4):397-414.

39. Almeida-Verdu ACM, Golfeto RM. Stimulus control and verbal behavior: (in)dependent relations in populations with minimal verbal repertoires. In:
Todorov JC (Ed.) Trends in behavior analysis, Vol 1. Brasília: Technopolitik Editora; 2016. p.187-227.

40. Brandau R, Monteiro R, Braile DM. Importância do uso correto dos descritores nos artigos científicos. Rev bras cir cardiovasc. 2005;20(1):7-9. 